\title{
Article \\ Training History-Dependent Functional Role of EMG Model-Predicted Antagonist Moments in Knee Extensor Moment Generation in Healthy Young Adults
}

\author{
Tibor Hortobágyi ${ }^{1,2,3,4} \mathbb{D}$, Paul DeVita ${ }^{5, *}$, Robert Brady ${ }^{5}$ and Patrick Rider 5 \\ 1 Center for Human Movement Sciences, University Medical Center Groningen, University of Groningen, \\ 9713AV Groningen, The Netherlands; t.hortobagyi@umcg.nl \\ 2 Somogy County Kaposi Mór Teaching Hospital, 7400 Kaposvár, Hungary \\ 3 Department of Sport Biology, Institute of Sport Sciences and Physical Education, University of Pécs, \\ 7624 Pécs, Hungary \\ 4 Division of Training and Movement Sciences, Research Focus Cognition Sciences, University of Potsdam, \\ 14469 Potsdam, Germany \\ 5 Department of Kinesiology, East Carolina University, Greenville, NC 27858, USA; \\ robert.bradydvm@gmail.com (R.B.); riderp@ecu.edu (P.R.) \\ * Correspondence: devitap@ecu.edu
}

Citation: Hortobágyi, T.; DeVita, P.; Brady, R.; Rider, P. Training History-Dependent Functional Role of EMG Model-Predicted Antagonist Moments in Knee Extensor Moment Generation in Healthy Young Adults. Biomechanics 2022, 2, 7-19. https:// doi.org/10.3390/biomechanics2010002

Received: 9 December 2021

Accepted: 5 January 2022

Published: 6 January 2022

Publisher's Note: MDPI stays neutral with regard to jurisdictional claims in published maps and institutional affiliations.

Copyright: (c) 2022 by the authors. Licensee MDPI, Basel, Switzerland. This article is an open access article distributed under the terms and conditions of the Creative Commons Attribution (CC BY) license (https:// creativecommons.org/licenses/by/ $4.0 /)$.

\begin{abstract}
Resistance training (RT) improves the skeletal muscle's ability to generate maximal voluntary force and is accompanied by changes in the activation of the antagonist muscle which is not targeted primarily by RT. However, the nature and role of neural adaptation to RT in the antagonist muscle is paradoxical and not well understood. We compared moments, agonist muscle activation, antagonist activation, agonist-antagonist coactivation, and electromyographic (EMG) model-predicted moments generated by antagonist hamstring muscle coactivation during isokinetic knee extension in leg strength-trained $(n=10)$ and untrained $(n=11)$ healthy, younger adults. Trained vs. untrained adults were up to $58 \%$ stronger. During knee extension, hamstring activation was 1.6-fold greater in trained vs. untrained adults $(p=0.022)$. This hamstring activation produced 2.6 -fold greater model-predicted antagonist moments during knee extension in the trained $(42.7 \pm 19.55 \mathrm{Nm})$ vs. untrained group $(16.4 \pm 12.18 \mathrm{Nm} ; p=0.004)$, which counteracted (reduced) quadriceps knee extensor moments $\sim 43 \mathrm{Nm}\left(0.54 \mathrm{Nm} \cdot \mathrm{kg}^{-1}\right)$ and by $\sim 16 \mathrm{Nm}\left(0.25 \mathrm{Nm} \cdot \mathrm{kg}^{-1}\right)$ in trained vs. untrained. Antagonist hamstring coactivation correlated with decreases and increases, respectively, in quadriceps moments in trained and untrained. The EMG model-predicted antagonist moments revealed training history-dependent functional roles in knee extensor moment generation.
\end{abstract}

Keywords: resistance training; muscle activation; neural adaptation; coactivation

\section{Introduction}

Resistance training (RT) improves the skeletal muscle's ability to generate maximal voluntary force, a primary outcome in rehabilitation medicine and athletic performance. In a uniarticular exercise such as knee extension, quadriceps agonist activation dominates along with some coactivation of the antagonist hamstrings [1,2]. The repeated, forceful contractions during RT induce adaptations in the central nervous system, increasing the activation of the trained, agonist muscle when tested under high loads or resistance [3-6]. The nature and role of neural adaptation to RT in the antagonist muscle is paradoxical. On the one hand, motor practice improves the focus of the neural command by increasing inhibition in muscles not targeted by the motor command (thereby minimizing antagonist coactivation) [7]. On the other hand, RT-induced increases in maximal voluntary force would necessitate an increase in coactivation of muscles not targeted by the training to protect and stabilize the joint against shear forces [8,9]. That is, while RT-related skill practice would tend to reduce agonist-antagonist coactivation, RT-induced improvements 
in agonists' force generation would increase the mechanical demand on the joint, requiring increases in antagonist coactivation for sake of joint stability.

Unsurprisingly, there is considerable inconsistency in how antagonist muscle coactivation adapts to chronic RT targeting the agonist muscle only, as it can decrease [10-12], not change [13-16], or even increase [17]. Antagonist response to RT is important since it balances shear forces across the trained joint $[8,9,18]$, and such an action plays a role in injury prevention [19] and orthopedic conditions including knee osteoarthritis [20,21]. Increasing agonist alone may increase potentially injurious unbalanced shear forces due to "one-sided training". Indeed, when elite junior high jumpers trained with plyometrics, training targeted the lower extremity extensor mechanism without supplemental hamstring training, giving rise to a potential imbalance between lower extremity extensors and flexors [22]. To minimize risks for hamstring injuries, RT would need to strengthen the disproportionately weakened hamstrings by 'one-sided training' [23-25]. Antagonist response to RT and other exercise interventions are important in rehabilitation of patients with stroke [26], multiple sclerosis [27], Parkinson's disease [28,29], and cerebral palsy [30], patients who all tend to exhibit heightened antagonist muscle activation linked to impaired motor performance [2].

Through a mathematical approach, we sought to clarify the functional relevance of antagonistic muscle coactivation during maximal effort knee extension and quadriceps effort by computing the counteracting moment of force generated by the antagonist hamstrings [1]. During a forceful isokinetic knee extension, the quadriceps generates an anteriorly shearing force of the tibia relative to the femur [31-33]. Activation of the antagonist knee flexors during knee extension provides stability to the knee by counteracting this shearing force $[8,9]$. By measuring the external moment of forces (moments) and muscle activation during knee extension and flexion, we examined the effects of RT history on agonist, antagonist, and agonist-antagonist coactivation and computed, based on these data, the magnitude of counteracting moments generated by the antagonist hamstrings during knee extension [1]. While previous RT studies produced inconsistent results with respect to changes in antagonist activation during knee extension [10-17], in view of more recent work, we hypothesized that coactivation would be lower in RT-trained than untrained healthy younger adults (generating lower moments and counteracting knee extension) [34] We included three speed conditions since contraction speed affects the agonist-antagonist activation pattern as hamstrings become strongly activated to decelerate the limb at the end of knee extension as speed increases. In this extended knee position, the shearing force also peaks [1]. We expect greater speed-sensitivity in agonist-antagonist activation profile of RT-trained compared with untrained adults. The purpose of this study was to compare moments, agonist muscle activation, antagonist activation, agonist-antagonist coactivation, and electromyographic (EMG) model-predicted moments generated by antagonist hamstring muscle activation during knee extension at three speeds in leg RT-trained and untrained, healthy, younger adults.

\section{Methods}

\subsection{Participants and Design}

Two groups of healthy younger adult volunteers were recruited from campus and surrounding areas. One group consisted of individuals $(n=10,6 \mathrm{M})$ with a history of RT of the lower extremities for at least one day per week for a minimum of six months prior to the start of the study. The other group consisted of sedentary individuals $(n=11,5 \mathrm{M})$ who engaged in no self-directed or organized physical activity (Table 1). Inclusion criteria were age 18 to 25, either gender, and willingness to sign an informed consent document. Exclusion criteria were past orthopedic surgeries or serious injuries in the lower extremities, current pain in the lower extremities, and suspicion or reported use of performance enhancing drugs. In this cross-sectional, observational study, participants visited the laboratory for one, 2-h-long session. Each participant read and signed an informed consent docu- 
ment which was approved by the University's Policy and Review Committee on Human Research. The study was conducted in accordance with the Declaration of Helsinki.

Table 1. Participant characteristics.

\begin{tabular}{ccc}
\hline Variable & Trained $(\boldsymbol{n}=\mathbf{1 0 , 4 F})$ & Untrained $(\boldsymbol{n}=\mathbf{1 1}, \mathbf{5 F})$ \\
\hline Age, $\mathrm{y}$ & $22.8 \pm 1.75$ & $21.1 \pm 2.55$ \\
Height, $\mathrm{cm}$ & $178.1 \pm 8.45$ & $171.1 \pm 12.10$ \\
Mass, $\mathrm{kg}$ & $78.9 \pm 13.08$ & $64.6 \pm 10.58^{*}$ \\
BMI, $\mathrm{kg} \cdot \mathrm{m}^{-2}$ & $24.7 \pm 2.25$ & $21.9 \pm 1.59 *$ \\
Quadriceps MVC, $\mathrm{Nm}$ & $216 \pm 88$ & $137 \pm 48^{*}$ \\
Quadriceps MVC, Nm $\cdot \mathrm{kg}^{-1}$ & $2.80 \pm 1.15$ & $2.20 \pm 0.97^{*}$ \\
Hamstring MVC, Nm & $202 \pm 84$ & $134 \pm 53^{*}$ \\
Hamstring MVC, $\mathrm{Nm} \cdot \mathrm{kg}^{-1}$ & $2.63 \pm 1.19$ & $2.10 \pm 0.63 *$
\end{tabular}

Values are mean \pm SD, BMI, body mass index, MVC, measured maximal voluntary contraction moments during quadriceps concentric and hamstring eccentric actions averaged across 30,90 , and $150^{\circ} / \mathrm{s} .{ }^{*} p<0.05$.

\subsection{Preparation for Measurements}

After the skin surface was shaved, cleaned with alcohol and abraded with LemonPrep, a pair of $\mathrm{Ag} / \mathrm{AgCl}, 2.0 \mathrm{~cm}$ center-to-center disposable surface electrodes (11 mm diameter each, EL503, Biopac Systems, Inc., Goleta, CA, USA) were affixed to the belly center of each of the following muscles: right vastus lateralis, vastus medialis, biceps femoris long head, and semitendinosus according to SENIAM conventions [35]. The ground electrode was attached to the fibula head. The stability of electrode placement and signal quality was checked during one-legged squats with and without a neoprene wrap around the thigh. For a general warm-up, participants rode a bicycle ergometer for $5 \mathrm{~min}$ at $1-2 \mathrm{~kg}$ resistance. Measurements on the dynamometry followed.

\subsection{Measurement of Quadriceps and Hamstring Maximal Moments}

Participants were seated on the padded seat of a computerized isokinetic dynamometer with the back support reclined by 5-10 (HUMAC Norm, Computer Sports Medicine Inc., Stoughton, MA, USA). The center of the right knee joint was visually aligned with the axis of rotation of dynamometer's power head. To minimize extraneous movements during the measurements, participants were stabilized by cross-over chest straps, a lap belt, and a thigh strap that did not interfere with the EMG sensors. The knee range of motion was set to $90^{\circ}$ to $10^{\circ}\left(0^{\circ}=\right.$ full extension). For a specific warm-up and familiarization with the task, participants performed two to three weak, medium strong, and forceful knee extensions and flexions at each speed.

In one task, participants maximally contracted the knee extensors concentrically (i.e., quadriceps agonist, hamstring antagonist). In a separate task, they maximally contracted the knee flexors eccentrically (i.e., hamstrings agonist, quadriceps antagonist). The quadriceps actively generated concentric moments. The hamstrings resisted the movement of the dynamometer's lever and generated eccentric moments. Each contraction type was carried out at 30,90, and $150^{\circ} / \mathrm{s}$. The order of contraction type and speed was randomized. Participants performed five to seven maximal effort trials with at least $90 \mathrm{~s}$ of rest between contractions and $3 \mathrm{~min}$ of rest between contraction type. The HUMAC Norm dynamometer is a valid and reliable instrument used as a gold standard in lower extremity muscle strength and power assessments [36-38]. The protocol is also reliable for the speeds and contraction types in the population examined here [39].

\subsection{Data Collection and Analyses}

The dynamometer's analog output provided the moment and position signals. The loadcell-recorded force was multiplied by the lever arm measured for each participant and external moments computed, which were corrected for the effects of gravity by the dynamometer's software. Each EMG sensor pair was connected with shielded cables 
to a preamplifier (common mode rejection ratio $\pm 100 \mathrm{~dB}$ ) (Myopac MPRD-101, Konigsberg Instruments, Inc., Pasadena, CA, USA), amplified 1000 $\times$ and band-pass filtered at $10-300 \mathrm{~Hz}$, rectified, and smoothed with a 20-ms window. The moment, position, and EMG signals were sampled at $960 \mathrm{~Hz}$ by the Qualisys Track Manager software (QTM, Qualisys, Göteborg, Sweden). The moment-position-time signals were exported from QTM and analyzed for the peak moment value in a Visual 3D pipeline. The three most consistent moment values from the five to seven trials collected in a given condition were averaged and included in the analyses, along with the position data. The moment and the rectified, smoothed EMG data were $10^{\circ}$-binned and the mean moment and mean EMG values computed within each bin. Using a mathematical model, we computed quadriceps and hamstring moments for each muscle when it was acting as an agonist or antagonist using EMG-to-force constants [1]. This computation allowed us to determine the net concentric moment as the measured quadriceps moment corrected for the moment that was generated by the antagonist activation. In the present paper we are not reporting the data for the quadriceps acting as an antagonist during knee flexion contractions. We thus compared between trained and untrained participants: (1) measured maximal concentric quadriceps and eccentric hamstring moments; (2) the moments generated by the hamstrings based on their EMG activation during knee extension; and (3) net concentric quadriceps moment which is the measured quadriceps moment minus the coactivation-generated hamstring moments. The difference between measured and calculated moments at the three speeds and in the two groups was $\sim 2 \%$, suggesting the internal validity of the data (detailed data not shown).

Quadriceps and hamstring activation were, respectively, computed as the average of the processed vastus lateralis and vastus medialis and biceps femoris and semitendinosus activity. Hamstring coactivation during knee extension was computed as: (1) the ratio of the hamstring activation relative to quadriceps activation in each $10^{\circ}$ bin (coactivation index 1 , COA1); (2) hamstring coactivation expressed relative to maximal hamstring activation measured during maximal hamstring eccentric contraction (coactivation index 2, COA2); and (3) hamstring coactivation relative to the peak quadriceps activation whichever $10^{\circ}$-bin it occurred (COA3).

\subsection{Statistical Analyses}

Data are expressed as mean \pm SD. Variables were normally distributed based on the Shapiro-Wilk test. The main analysis was a three-way analysis of variance using training status (trained, untrained) as a between factor and speed $\left(30,90,150^{\circ} / \mathrm{s}\right)$ and the eight bins as repeated measures, to determine the effects of these variables on moment and EMG outcomes. The main and interaction effects were characterized by partial eta squared $\left(\mathrm{p \eta}^{2}\right)$ effect size. Significant interactions were followed by a Tukey's posthoc to determine the means that were different. Cutoffs for $\mathrm{p}^{2}$ are $\geq 0.01$ (small), $\geq 0.06$ (medium), and $\geq 0.14$ (large). Simple effects were also quantified by Cohen's effect size, $d$ (small: 0.20; moderate: 0.50; large: 0.80 ). We used Person product moment correlation to examine the relationship between measured quadriceps moment and hamstring to quadriceps coactivation ratios in each group. The level of significance was set at $p<0.05$. All analyses were performed in SPSS (version 25.0).

\section{Results}

Table 1 shows that the two groups of participants. The two groups had similar gender distribution, age, and height. The trained vs. untrained group had $14.3 \mathrm{~kg}$ and $2 \mathrm{~kg} \cdot \mathrm{m}^{-2}$ higher body mass and body mass index. The trained vs. untrained group's maximal voluntary quadriceps concentric moments (averaged across the three speeds) were $58 \%$ (not normalized for body mass) and $27 \%$ (normalized) higher. The maximal voluntary hamstring eccentric moments (averaged across the three speeds) were $51 \%$ (not normalized) and 25\% (normalized) higher (all differences $p<0.001$, all $0.60 \leq \mathrm{d} \geq 1.34$ ). 


\subsection{Muscle Activation and Coactivation}

Figure 1 shows quadriceps agonist activation and hamstring antagonist activation during knee extension in the two groups, three speeds, and eight bins. The three-way interaction $\left(\mathrm{F}=2.6, p=0.002, \mathrm{p \eta}^{2}=0.219\right)$ revealed that activation increased more toward the middle of the range of motion in the trained vs. untrained group in which the differences in activation were smaller between speeds. Quadriceps activation was 2.0 -fold or $0.32 \mathrm{mV}$ greater in the trained $(0.64 \mathrm{mV} \pm 0.15)$ than in the untrained group $(0.32 \mathrm{mV} \pm 0.13, \mathrm{~F}=7.5$, $\left.p=0.013, \mathrm{p \eta}^{2}=0.482\right)$. Figure 1 also shows the group by speed by bin interaction $(\mathrm{F}=1.8$, $\left.p=0.047, \mathrm{p \eta}^{2}=0.182\right)$ in hamstring activation during knee extension. The activation was more speed-sensitive and increased more in the trained vs. untrained across the eight bins. Hamstring activation was 1.6 -fold or $0.03 \mathrm{mV}$ greater in the trained $(0.09 \pm 0.021)$ than in the untrained group $\left(0.06 \pm 0.048 \mathrm{mV}, \mathrm{F}=4.9, p=0.022, \mathrm{p}^{2}=0.182\right)$.
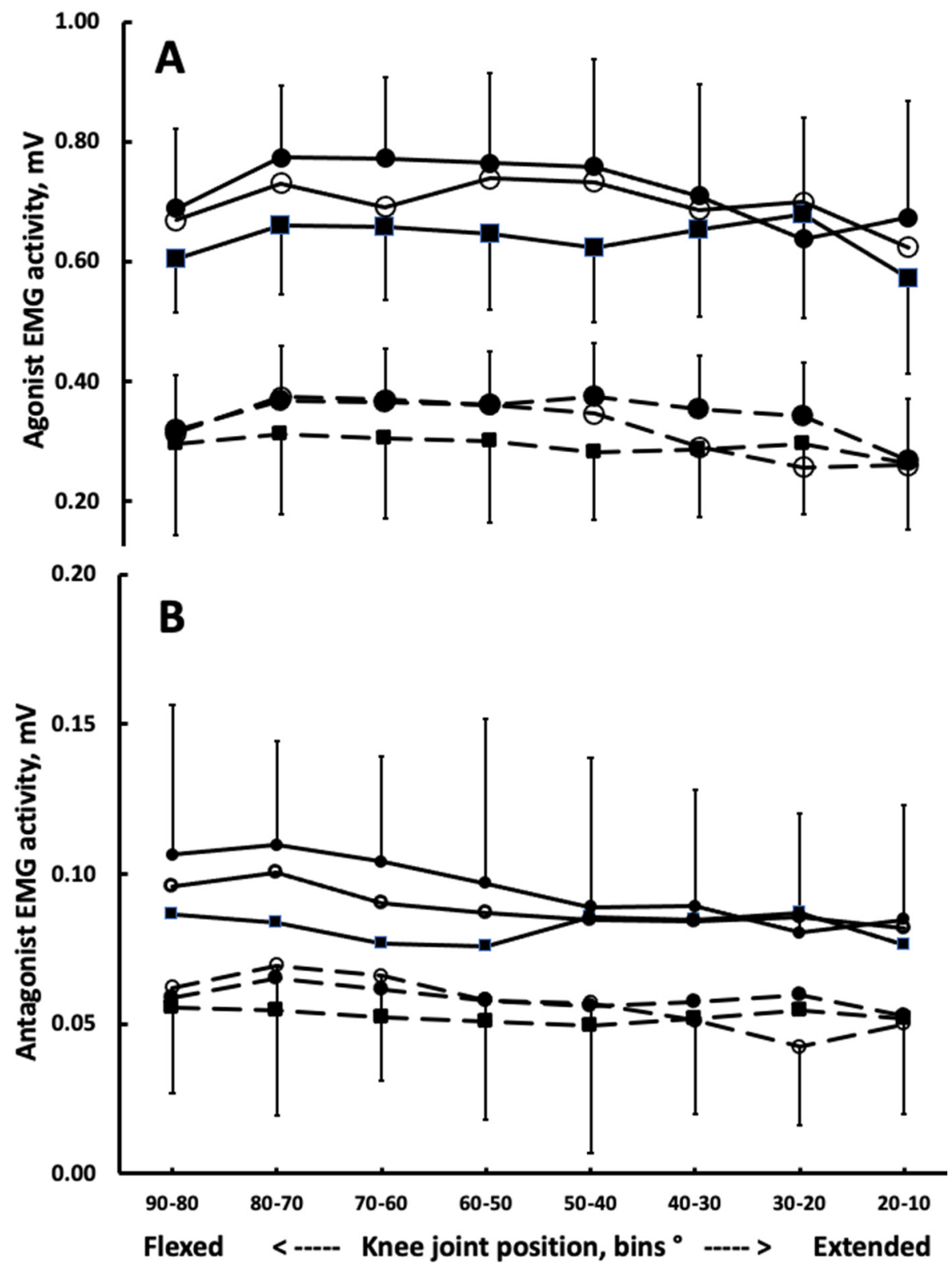

Figure 1. Quadriceps agonist activation (A) and hamstring antagonist activation (B) during knee extension at 30 (filled circles), 90 (unfilled circles), $150^{\circ} \cdot \mathrm{s}^{-1}$ (filled squares). Solid lines denote trained, dashed lines denote untrained participants Vertical bars denote + or $-1 S D$, displayed for selected speeds for clarity. Note the different vertical scales in panels A and B. 
Figure 2 shows the group by method of computing coactivation (COA1, COA2, COA3, $\left.\mathrm{F}=3.2, p=0.039, \mathrm{p}^{2}=0.108\right)$. COA1 was $64 \%$ higher in untrained vs. trained $(p=0.001$, $\mathrm{d}=0.79)$. COA2 was $23 \%( \pm 11.39)$ in the trained and $22 \%( \pm 10.14)$ in the untrained. COA3 was $16 \%( \pm 6.01)$ in the trained and $17 \%( \pm 5.82)$ in the untrained group (COA2 and COA3 $p \geq 0.382$ ). For these quotients, there were no group by speed by bin or other two-way interactions (all $p>0.05)$.

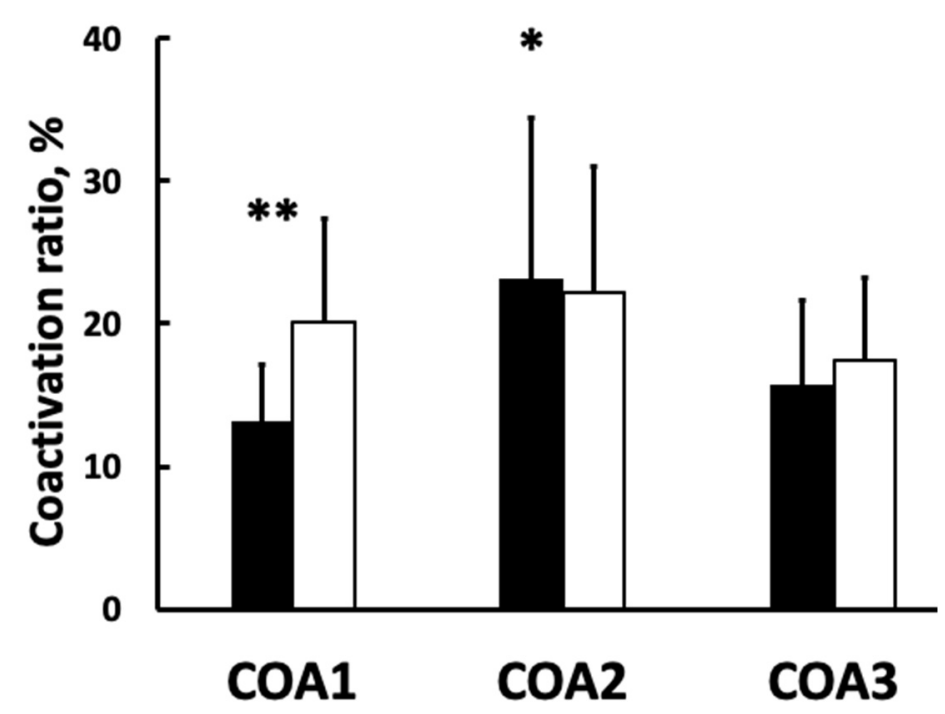

Figure 2. Hamstring antagonist coactivation computed as the ratio between hamstring antagonist activation relative to quadriceps agonist activation during knee extension (coactivation index 1, COA1), hamstring antagonist activation during knee extension expressed relative to hamstring agonist activity measured during maximal eccentric contraction (coactivation index 2, COA2), and COA3) hamstring coactivation relative to the peak quadriceps activation whichever $10^{\circ}$-bin it occurred (COA3). For each COA, data are pooled across three speeds $\left(30,90,150^{\circ} \cdot \mathrm{s}^{-1}\right)$ and eight bins. Filled columns: Trained. Unfilled columns: Untrained. * Group by Method of computing COA interaction and ${ }^{* *}$ Trained lower vs. Untrained $(p<0.05)$. Vertical bars: $+1 \mathrm{SD}$.

\subsection{Moments Data}

Figure 3 shows the moments data. For quadriceps agonist moments measured during knee extension, the group by speed by bin interaction was not significant $(p=0.332)$. There was no group by speed interaction $\left(\mathrm{F}=1.6, p=0.223, \mathrm{p}^{2}=0.080\right)$ but the group by bin interaction $\left(\mathrm{F}=3.4, p=0.002, \mathrm{p}^{2}=0.260\right)$ showed steeper relationship between moment and joint position in the trained vs. untrained group, corresponding to the muscle activation pattern in Figure 1. The group main effect $\left(\mathrm{F}=6.6, p=0.019, \mathrm{p} \eta^{2}=0.369\right)$ revealed a 1.6-fold greater bin-averaged knee extension moment in favor of the trained vs. untrained group (see also Table 1 for maximal moments). Figure 3 also shows the model-computed moments generated by hamstring activation during knee extension. Of the relevant effects, only the group main effect was significant $\left(F=5.9, p=0.004, \mathrm{p}^{2}=0.383\right)$ revealing 2.6-fold greater model-predicted antagonist moments during knee extension in the trained (42.7 $\mathrm{Nm} \pm 19.55)$ vs. untrained group (16.4 Nm \pm 12.18$)$. Thus, the hamstring activation-generated moments counteracted (reduced) quadriceps knee extensor moments by $\sim 2.4$-fold more, by $\sim 43 \mathrm{Nm}\left(0.54 \mathrm{Nm} \cdot \mathrm{kg}^{-1}\right)$ and $\sim 16 \mathrm{Nm}\left(0.25 \mathrm{Nm} \cdot \mathrm{kg}^{-1}\right)$ in trained and untrained, respectively. 


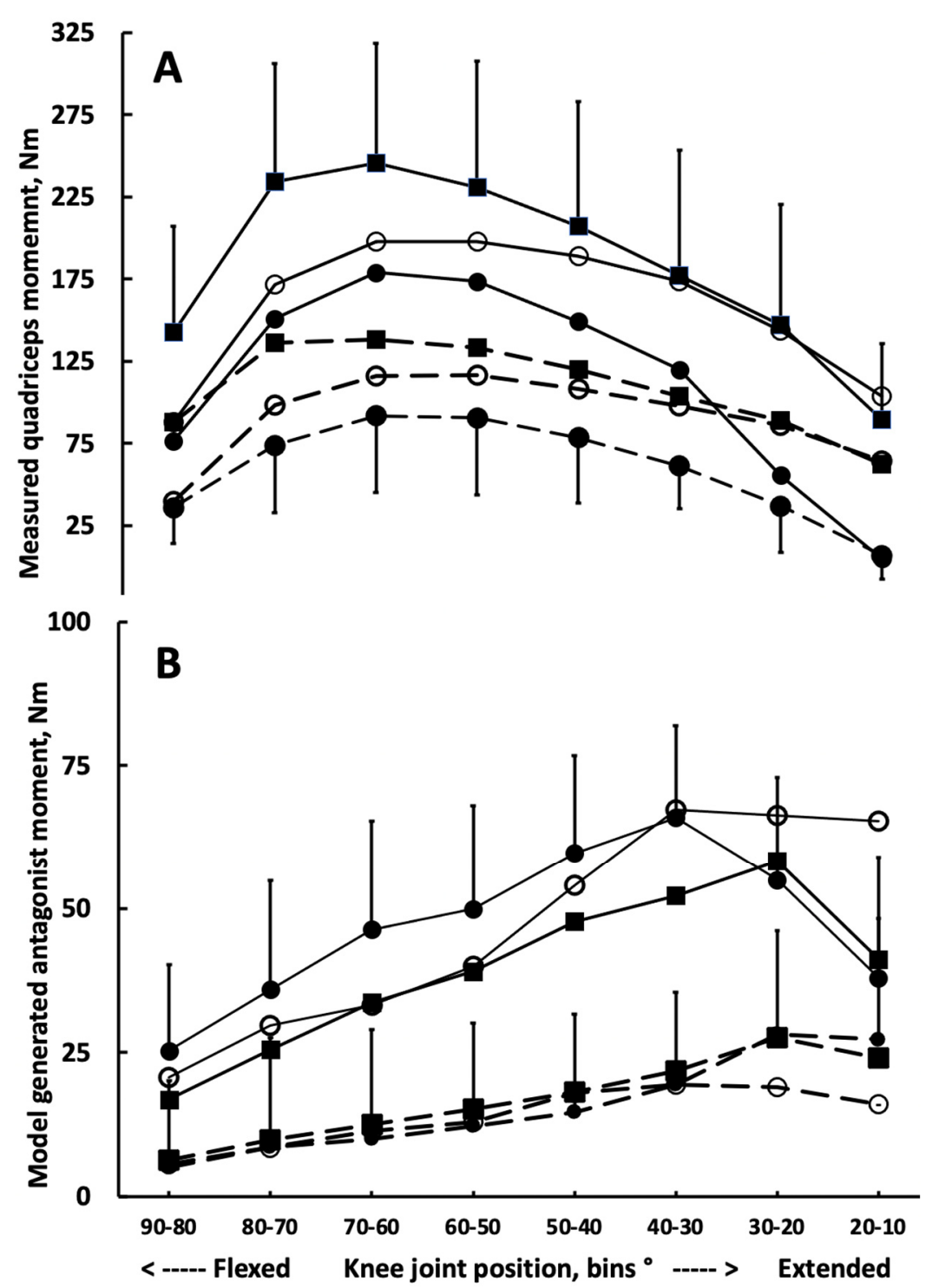

Figure 3. Measured quadriceps agonist concentric moments averaged in $10^{\circ}$ bins during knee extension at 30 (filled circles), 90 (unfilled circles), $150^{\circ} \cdot \mathrm{s}^{-1}$ (filled squares, (A)). Model-predicted moments generated by the hamstrings during knee extension at 30 (filled circles), 90 (unfilled circles), $150^{\circ} \cdot \mathrm{s}^{-1}$ (filled squares, (B)) In both panels, the upper set of three solid lines is for trained and the lower set of 3 dashed lines is for untrained participants. Vertical bars denote + or $-1 \mathrm{SD}$, displayed for only selected speeds for clarity.

\subsection{Correlations}

Figure 4 shows that the relationship between measured quadriceps moment and COA1 was negative trained and positive in untrained. 

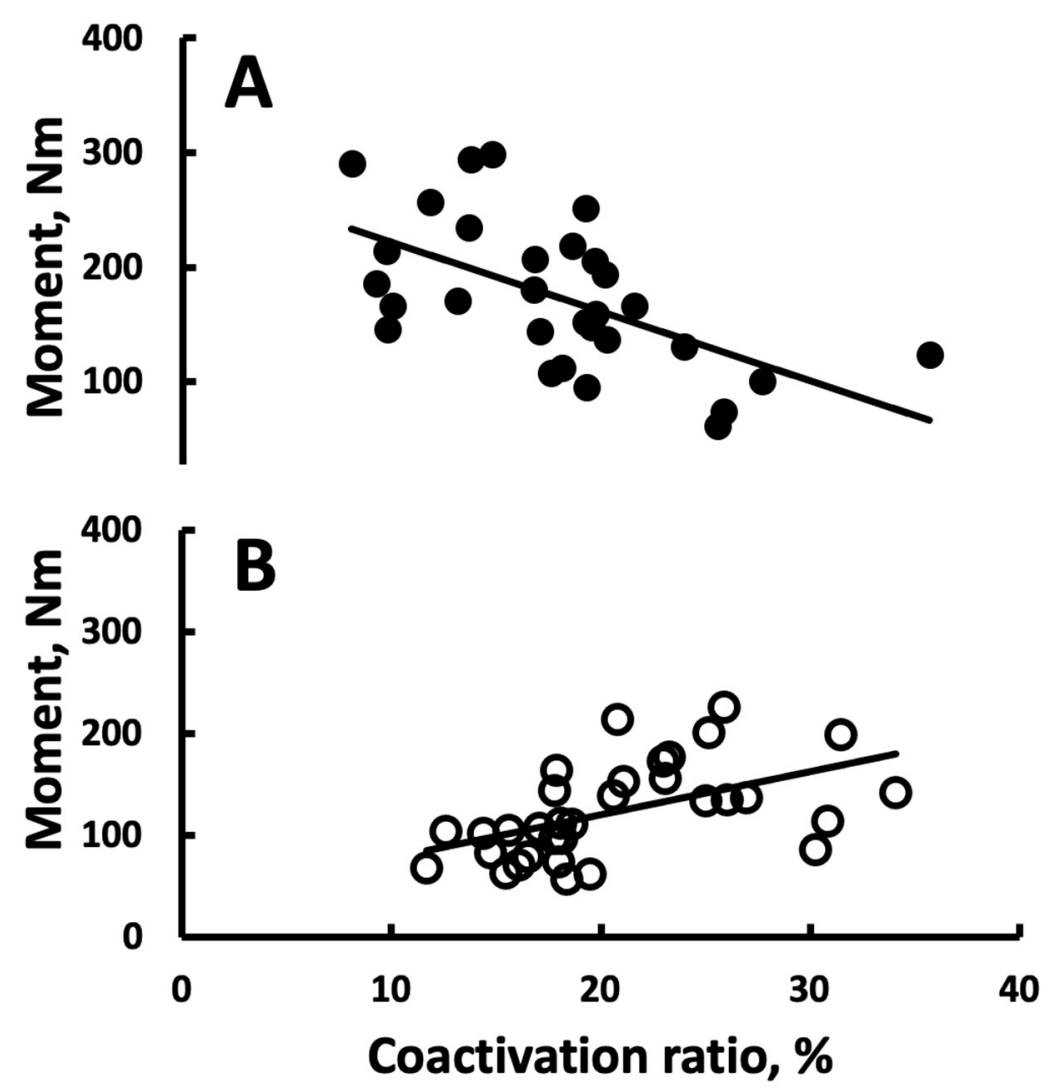

Figure 4. Relationship between measured quadriceps moment and hamstring to quadriceps coactivation ratio (COA1) in the trained (A) and untrained (B) group. Each participant has one value at 30,90 , and $150^{\circ} \cdot \mathrm{s}^{-1}$ with each of these values comprising muscle activation data averaged for eight bins over the range of motion. The relationship is characterized by the equation $y=-8.1 \mathrm{x}+282.7$, $\mathrm{R}^{2}=0.34, p=0.001(\mathrm{~A})$ and $\mathrm{y}=4.2 \mathrm{x}+36.0$ and $\mathrm{R}^{2}=0.27, p=0.002$.

\section{Discussion}

We compared moments, agonist muscle activation, antagonist muscle activation, and EMG model-predicted moments generated by antagonist hamstring muscle activation during knee extension in leg strength-trained and untrained healthy, younger adults. Trained vs. untrained had up to $58 \%$ higher leg muscle strength, different quadriceps and hamstring activation profiles during isokinetic knee extension, accompanied by inconsistent levels of antagonist coactivation. These data partially support the hypothesized lower coactivation in RT-trained than untrained participants, as the type of coactivation ratio affected coactivation. However, the EMG model-predicted antagonist moments were $\sim 2.6$-fold greater in trained than untrained, contradicting the second part of the hypothesis. Despite lower hamstrings co-activation in trained vs. untrained, their greater hamstrings eccentric strength used in the model led to the higher antagonist moments in this group. At the individual level, antagonist hamstring coactivation was associated with decreases and increases, respectively, in quadriceps moments in trained and untrained. To ensure clarity and consistency, coactivation is a ratio between hamstring and quadriceps activation in contrast to the hamstring activation during knee extension, which is not references to quadriceps activation (Figure 1, panel B).

For the first time, we estimated the moments hamstring activation generated during knee extension in RT-trained healthy young adults. As expected, higher hamstring activation in the trained $(42.7 \mathrm{Nm} \pm 19.55)$ vs. untrained (16.4 Nm \pm 12.18$)$ produced 2.6-fold greater EMG-model-predicted hamstring moments during knee extension. The activation-based, model-predicted hamstring moments would reduce maximal measured knee extension moments by $20 \%$ vs. $12 \%$ in trained vs. untrained. This approach assigns 
functional relevance to hamstring activation during knee extension and could help to check exercise training and other intervention effects on neuromuscular control in athletes and patients. The functional relevance of hamstrings co-activation can be exemplified by the moment data in the $60-70^{\circ}$ bin. With a correction for the predicted hamstrings moment, the observed quadriceps moments at $60-70^{\circ}$ of knee flexion would be 242 and $127 \mathrm{Nm}$ in trained and untrained groups. The difference in quadriceps strength would be $91 \%$ and not $53 \%$ in this case.

Such an approach is perhaps favored over extracting functional or mechanistic information from EMG-based coactivation indices. Indeed, Figure 3 shows hamstring antagonist to quadriceps agonist coactivation quantified in three most often reported ways in the literature (i.e., COA1, COA2, COA3). The results were inconsistent, as trained vs. untrained had lower coactivation only when antagonist hamstring activation was expressed relative to agonist quadriceps activation (pooled across three speeds, eight bins) but not when using the two other referencing schemes. While coactivation is interpreted as a hallmark of neural adaptations to RT due to motor learning, [3] there is no consensus as to how RT or other interventions modify agonist-referenced agonist-antagonist coactivation. After RT interventions, agonist-referenced agonist-antagonist coactivation decreased [10-12], did not change [13-16] or increased [17]. Such inconsistencies are also reflected by the current (Figure 1) and past cross-sectional data [40]. One reason for inconsistencies could be that the method of computing coactivation produces different results (Figure 1). Still, our EMG coactivation data provide a hint at its functional relevance, as the relationship between measured quadriceps moment and hamstring to quadriceps coactivation ratio (COA1) was significant but opposite in direction in the two groups (Figure 3). One interpretation of these data is that motor learning modifies extensor-flexor inter-muscular balance which facilitates strength gains in the target agonist muscle after RT, whereas the role of coactivation in untrained individuals is to increase joint stability. It thus appears that computing the moments based on the activation antagonist muscles generate during movements brought about by activation of agonist muscles, would increase our understanding the intervention-induced adaptations in neuromuscular control in health and disease.

Quadriceps agonist activation was 2.0-fold greater in the trained than in the untrained group (Figure 1), paralleling group-differences in the moment-velocity relationship (Figure 3). These data agree with most [40-43] but not all [44] cross-sectional studies showing RT-trained compared with untrained individuals having higher muscle activation during forceful isometric and dynamic contractions of the agonist muscles. With an understanding of the limitations of sEMG [45-48] as used in some of these [40-42] and the present study, the higher sEMG activation is interpreted as neural adaptations to RT. The causes of such adaptations are multitude but seem to include RT-induced increases in motor neuron output from the spinal cord to the muscle through decreases in the recruitmentthreshold force of motor units, increases in motor unit discharge rates, synaptic input to the motor neuron pool or to adaptations in intrinsic motor neuron properties [43,49]. The functional relevance of these changes is still not entirely clear, as long-term RT seem to cause no changes in brain maps underlying the neural drive to muscle [40] and since changes in sEMG and other measures of neural adaptations to RT in the agonist muscle are in most studies (if reported) poorly or not correlated with changes in muscle strength $[3,50]$ (Figure 4).

Previously unexamined, quadriceps and hamstring activation profiles and sensitivity of this activation to speed during isokinetic knee extension differed by training status. The quadriceps agonist activation was more speed-sensitive and increased more in trained vs. untrained across the eight bins (Figure 2). RT intervention studies revealed that architectural changes in muscle are not uniform, as proximal vs. distal changes are greater in cross-sectional area and fascicle length of the trained quadriceps [50]. Such architectural adaptations could underlie the earlier and steeper rise in activation across the range of motion from flexed to extended knee joint position in trained vs. untrained, mimicking the moment-velocity profiles (Figures 1 and 3). The different agonist activation profile observed 
here is probably not related to instantaneous fatigue developing during contraction since RT seems not to affect fatigability measured during contraction [51].

Quadriceps agonist activation was more sensitive to contraction speed in the trained than untrained group (Figure 1). These data agree with the monotonic, flat pattern of agonist muscle activation in untrained, healthy adults in the upper and lower extremity muscles [52-55]. In the trained group, the most and least activation at 30 and $150^{\circ} \cdot \mathrm{s}^{-1}$ occurred in the early bins across the range of motion (i.e., at the start of knee extension). These data are consistent with the idea that muscle activation increases with increasing moments and that a greater muscle mass is activated more effectively at all contraction speeds. Gait data also supports this contention [56,57]. High moments and muscle mass require greater activation compared with the activation needed during isokinetic contractions of increasing speed.

Hamstring antagonist activation during knee extension was 1.6-fold greater in the trained than in the untrained group (data pooled across three speeds, eight bins) (Figure 1). The hamstring activation data parallel the between-group differences in hamstring moments and imply adaptations in hamstring activation during knee extension after chronic RT. A comparison of our data with RT intervention studies is not possible since these studies report hamstring antagonist to quadriceps agonist coactivation but not hamstring activation during a knee extension test per se. In another cross-sectional study, absolute and normalized hamstring activation during knee extension did not differ between RT-trained and untrained subjects, disagreeing with our data, but the way hamstring activation was expressed (e.g., relative to hamstring moments) affected the comparisons and conclusions [40].

One limitation of the present study is that we were unable to credibly verify training history in the trained participants who reported to have been training for up to six years and were up to $\sim 53 \%$ stronger. Since body mass and body mass index were higher in the trained vs. untrained adults, reflecting presumably differences in lean mass, the effects of subcutaneous fat thickness under the electrodes are likely to affect group-differences in sEMG minimally but we did not measure this. Multi-array EMG recording provides the distribution and the wave of activation, information we were unable to acquire with electrode pairs. The cross-sectional design prevents us from drawing any mechanistic inferences from the data.

Implications of the current data for strength training are to have athletes' strengthtrain muscles pairs in a balanced manner so that training involves not only agonist muscle groups activated primarily in a skill but the antagonist muscles as well. Future studies could experimentally examine the effects of agonist-only, antagonist-only, and agonist-antagonist strength training on neural and mechanical functions as assessed by the mathematical model used herein. To expand the functional relevance of the current data, these studies should examine the relationship between the model-predicted changes in knee join moments and moments measured during the target skill.

\section{Conclusions}

RT-trained vs. untrained healthy younger adults, with up to $53 \%$ higher knee extension strength, had different quadriceps and hamstring activation profiles during isokinetic knee extension. EMG model-predicted antagonist moments revealed training history-dependent functional roles in knee extensor moment generation.

Author Contributions: T.H., P.D., R.B. and P.R. contributed to study design, data collection, analysis, and interpretation, and the drafting, revising, and finalizing of the manuscript. All authors have read and agreed to the published version of the manuscript.

Funding: This research received no external funding.

Institutional Review Board Statement: The study was conducted in accordance with the Declaration of Helsinki, and approved by the Institutional Review Board of East Carolina University, Greenville, NC 27858, protocol number: UMCIRB \#11-0208, 5 April 2011. 
Informed Consent Statement: Informed consent was obtained from all subjects involved in the study.

Data Availability Statement: The datasets analyzed in the current study are available from the first author upon a reasonable request.

Conflicts of Interest: The authors declare no conflict of interest.

\section{References}

1. Aagaard, P.; Simonsen, E.B.; Andersen, J.L.; Magnusson, S.P.; Bojsen-Moller, F.; Dyhre-Poulsen, P. Antagonist muscle coactivation during isokinetic knee extension. Scand. J. Med. Sci. Sports 2000, 10, 58-67. [CrossRef]

2. Latash, M.L. Muscle coactivation: Definitions, mechanisms, and functions. J. Neurophysiol. 2018, 120, 88-104. [CrossRef] [PubMed]

3. Hortobágyi, T.; Granacher, U.; Fernandez-Del-Olmo, M.; Howatson, G.; Manca, A.; Deriu, F.; Taube, W.; Gruber, M.; Marquez, G.; Lundbye-Jensen, J.; et al. Functional relevance of resistance training-induced neuroplasticity in health and disease. Neurosci. Biobehav. Rev. 2021, 122, 79-91. [CrossRef] [PubMed]

4. Maeo, S.; Balshaw, T.G.; Lanza, M.B.; Hannah, R.; Folland, J.P. Corticospinal excitability and motor representation after long-term resistance training. Eur. J. Neurosci. 2021, 53, 3416-3432. [CrossRef]

5. Skarabot, J.; Brownstein, C.G.; Casolo, A.; Del Vecchio, A.; Ansdell, P. The knowns and unknowns of neural adaptations to resistance training. Eur. J. Appl. Physiol. 2021, 121, 675-685. [CrossRef] [PubMed]

6. Pearcey, G.E.P.; Alizedah, S.; Power, K.E.; Button, D.C. Chronic resistance training: Is it time to rethink the time course of neural contributions to strength gain? Eur. J. Appl. Physiol. 2021, 121, 2413-2422. [CrossRef]

7. Sugawara, K.; Tanabe, S.; Higashi, T.; Suzuki, T.; Tsurumi, T.; Kasai, T. Functional plasticity of surround inhibition in the motor cortex during single finger contraction training. Neuroreport 2012, 23, 663-667. [CrossRef] [PubMed]

8. Baratta, R.; Solomonow, M.; Zhou, B.H.; Letson, D.; Chuinard, R.; D'Ambrosia, R. Muscular coactivation. The role of the antagonist musculature in maintaining knee stability. Am. J. Sports Med. 1988, 16, 113-122. [CrossRef]

9. Solomonow, M.; Baratta, R.; Zhou, B.H.; Shoji, H.; Bose, W.; Beck, C.; D'Ambrosia, R. The synergistic action of the anterior cruciate ligament and thigh muscles in maintaining joint stability. Am. J. Sports Med. 1987, 15, 207-213. [CrossRef]

10. Carolan, B.; Cafarelli, E. Adaptations in coactivation after resistance training. J. Appl. Physiol. 1992, 73, 911-917. [CrossRef]

11. Häkkinen, K.; Kallinen, M.; Izquierdo, M.; Jokelainen, K.; Lassila, H.; Malkia, E.; Kraemer, W.J.; Newton, R.U.; Alen, M. Changes in agonist-antagonist EMG, muscle CSA, and force during strength training in middle-aged and older people. J. Appl. Physiol. 1998, 84, 1341-1349. [CrossRef] [PubMed]

12. Simoneau, E.; Martin, A.; Van Hoecke, J. Adaptations to long-term strength training of ankle joint muscles in old age. Eur. J. Appl. Physiol. 2007, 100, 507-514. [CrossRef]

13. Morse, C.I.; Thom, J.M.; Mian, O.S.; Muirhead, A.; Birch, K.M.; Narici, M.V. Muscle strength, volume and activation following 12-month resistance training in 70-year-old males. Eur. J. Appl. Physiol. 2005, 95, 197-204. [CrossRef]

14. de Boer, M.D.; Morse, C.I.; Thom, J.M.; de Haan, A.; Narici, M.V. Changes in antagonist muscles' coactivation in response to strength training in older women. J. Gerontol. A Biol. Sci. Med. Sci. 2007, 62, 1022-1027. [CrossRef] [PubMed]

15. Holtermann, A.; Roeleveld, K.; Vereijken, B.; Ettema, G. Changes in agonist EMG activation level during MVC cannot explain early strength improvement. Eur. J. Appl. Physiol. 2005, 94, 593-601. [CrossRef]

16. Reeves, N.D.; Maganaris, C.N.; Narici, M.V. Plasticity of dynamic muscle performance with strength training in elderly humans. Muscle Nerve 2005, 31, 355-364. [CrossRef]

17. Simoneau, E.; Martin, A.; Porter, M.M.; Van Hoecke, J. Strength training in old age: Adaptation of antagonist muscles at the ankle joint. Muscle Nerve 2006, 33, 546-555. [CrossRef] [PubMed]

18. Wilk, K.E.; Escamilla, R.F.; Fleisig, G.S.; Barrentine, S.W.; Andrews, J.R.; Boyd, M.L. A comparison of tibiofemoral joint forces and electromyographic activity during open and closed kinetic chain exercises. Am. J. Sports Med. 1996, 24, 518-527. [CrossRef] [PubMed]

19. Kvist, J.; Gillquist, J. Sagittal plane knee translation and electromyographic activity during closed and open kinetic chain exercises in anterior cruciate ligament-deficient patients and control subjects. Am. J. Sports Med. 2001, 29, 72-82. [CrossRef]

20. Messier, S.P.; Beavers, D.P.; Loeser, R.F.; Carr, J.J.; Khajanchi, S.; Legault, C.; Nicklas, B.J.; Hunter, D.J.; Devita, P. Knee joint loading in knee osteoarthritis: Influence of abdominal and thigh fat. Med. Sci. Sports Exerc. 2014, 46, 1677-1683. [CrossRef]

21. Messier, S.P.; Pater, M.; Beavers, D.P.; Legault, C.; Loeser, R.F.; Hunter, D.J.; DeVita, P. Influences of alignment and obesity on knee joint loading in osteoarthritic gait. Osteoarthr. Cartil. 2014, 22, 912-917. [CrossRef]

22. Hortobágyi, T. Training planning of junior high jumpers. In Planning of Training Series; Hortobágyi, T., Ed.; National Strength and Conditioning Association: Lincoln, NE, USA, 1989; pp. 1-28.

23. Chavarro-Nieto, C.; Beaven, M.; Gill, N.; Hebert-Losier, K. Hamstrings injury incidence, risk factors, and prevention in Rugby Union players: A systematic review. Physician Sportsmed. 2021, 1-19. [CrossRef] [PubMed]

24. Llurda-Almuzara, L.; Labata-Lezaun, N.; Lopez-de-Celis, C.; Aiguade-Aiguade, R.; Romani-Sanchez, S.; Rodriguez-Sanz, J.; Fernandez-de-Las-Penas, C.; Perez-Bellmunt, A. Biceps Femoris Activation during Hamstring Strength Exercises: A Systematic Review. Int. J. Environ. Res. Public Health 2021, 18, 8733. [CrossRef] [PubMed] 
25. Claudino, J.G.; Cardoso Filho, C.A.; Bittencourt, N.F.N.; Goncalves, L.G.; Couto, C.R.; Quintao, R.C.; Reis, G.F.; de Oliveira Junior, O.; Amadio, A.C.; Boullosa, D.; et al. Eccentric Strength Assessment of Hamstring Muscles with New Technologies: A Systematic Review of Current Methods and Clinical Implications. Sports Med. Open 2021, 7, 10. [CrossRef]

26. Kitatani, R.; Ohata, K.; Sato, S.; Watanabe, A.; Hashiguchi, Y.; Yamakami, N.; Sakuma, K.; Yamada, S. Ankle muscle coactivation and its relationship with ankle joint kinematics and kinetics during gait in hemiplegic patients after stroke. Somat. Mot. Res. 2016, 33, 79-85. [CrossRef] [PubMed]

27. Cofre Lizama, L.E.; Bastani, A.; van der Walt, A.; Kilpatrick, T.; Khan, F.; Galea, M.P. Increased ankle muscle coactivation in the early stages of multiple sclerosis. Mult. Scler. J.-Exp. Transl. Clin. 2020, 6, 2055217320905870. [CrossRef]

28. Arias, P.; Espinosa, N.; Robles-Garcia, V.; Cao, R.; Cudeiro, J. Antagonist muscle co-activation during straight walking and its relation to kinematics: Insight from young, elderly and Parkinson's disease. Brain Res. 2012, 1455, 124-131. [CrossRef]

29. Hirai, H.; Miyazaki, F.; Naritomi, H.; Koba, K.; Oku, T.; Uno, K.; Uemura, M.; Nishi, T.; Kageyama, M.; Krebs, H.I. On the Origin of Muscle Synergies: Invariant Balance in the Co-activation of Agonist and Antagonist Muscle Pairs. Front. Bioeng. Biotechnol. 2015, 3, 192. [CrossRef]

30. Unnithan, V.B.; Dowling, J.J.; Frost, G.; Bar-Or, O. Role of cocontraction in the $\mathrm{O} 2$ cost of walking in children with cerebral palsy. Med. Sci. Sports Exerc. 1996, 28, 1498-1504. [CrossRef] [PubMed]

31. Nisell, R.; Ericson, M.O.; Nemeth, G.; Ekholm, J. Tibiofemoral joint forces during isokinetic knee extension. Am. J. Sports Med. 1989, 17, 49-54. [CrossRef]

32. Beynnon, B.; Howe, J.G.; Pope, M.H.; Johnson, R.J.; Fleming, B.C. The measurement of anterior cruciate ligament strain in vivo. Int. Orthop. 1992, 16, 1-12. [CrossRef] [PubMed]

33. Hirokawa, S.; Solomonow, M.; Lu, Y.; Lou, Z.P.; D'Ambrosia, R. Anterior-posterior and rotational displacement of the tibia elicited by quadriceps contraction. Am. J. Sports Med. 1992, 20, 299-306. [CrossRef]

34. Balshaw, T.G.; Massey, G.J.; Maden-Wilkinson, T.M.; Lanza, M.B.; Folland, J.P. Neural adaptations after 4 years vs. 12 weeks of resistance training vs. untrained. Scand. J. Med. Sci. Sports 2019, 29, 348-359. [CrossRef] [PubMed]

35. Hermens, H.J.; Freriks, B.; Disselhorst-Klug, C.; Rau, G. Development of recommendations for SEMG sensors and sensor placement procedures. J. Electromyogr. Kinesiol. 2000, 10, 361-374. [CrossRef]

36. Habets, B.; Staal, J.B.; Tijssen, M.; van Cingel, R. Intrarater reliability of the Humac NORM isokinetic dynamometer for strength measurements of the knee and shoulder muscles. BMC Res. Notes 2018, 11, 15. [CrossRef]

37. Whinton, A.K.; Thompson, K.M.A.; Power, G.A.; Burr, J.F. Testing a novel isokinetic dynamometer constructed using a 1080 Quantum. PLoS ONE 2018, 13, e0201179. [CrossRef] [PubMed]

38. de Araujo Ribeiro Alvares, J.B.; Rodrigues, R.; de Azevedo Franke, R.; da Silva, B.G.; Pinto, R.S.; Vaz, M.A.; Baroni, B.M. Inter-machine reliability of the Biodex and Cybex isokinetic dynamometers for knee flexor/extensor isometric, concentric and eccentric tests. Phys. Ther. Sport 2015, 16, 59-65. [CrossRef]

39. Hortobagyi, T.; Zheng, D.; Weidner, M.; Lambert, N.J.; Westbrook, S.; Houmard, J.A. The influence of aging on muscle strength and muscle fiber characteristics with special reference to eccentric strength. J. Gerontol. A Biol. Sci. Med. Sci. 1995, 50, B399-B406. [CrossRef] [PubMed]

40. Balshaw, T.G.; Massey, G.J.; Maden-Wilkinson, T.M.; Morales-Artacho, A.J.; McKeown, A.; Appleby, C.L.; Folland, J.P. Changes in agonist neural drive, hypertrophy and pre-training strength all contribute to the individual strength gains after resistance training. Eur. J. Appl. Physiol. 2017, 117, 631-640. [CrossRef] [PubMed]

41. Amarantini, D.; Bru, B. Training-related changes in the EMG-moment relationship during isometric contractions: Further evidence of improved control of muscle activation in strength-trained men? J. Electromyogr. Kinesiol. 2015, 25, 697-702. [CrossRef]

42. Orssatto, L.B.R.; Wiest, M.J.; Moura, B.M.; Collins, D.F.; Diefenthaeler, F. Neuromuscular determinants of explosive torque: Differences among strength-trained and untrained young and older men. Scand. J. Med. Sci. Sports 2020, 30, 2092-2100. [CrossRef] [PubMed]

43. Vila-Cha, C.; Falla, D.; Farina, D. Motor unit behavior during submaximal contractions following six weeks of either endurance or strength training. J. Appl. Physiol. 2010, 109, 1455-1466. [CrossRef] [PubMed]

44. Daniels, R.J.; Cook, S.B. Effect of instructions on EMG during the bench press in trained and untrained males. Hum. Mov. Sci. 2017, 55, 182-188. [CrossRef]

45. Besomi, M.; Hodges, P.W.; Clancy, E.A.; Van Dieen, J.; Hug, F.; Lowery, M.; Merletti, R.; Sogaard, K.; Wrigley, T.; Besier, T.; et al. Consensus for experimental design in electromyography (CEDE) project: Amplitude normalization matrix. J. Electromyogr. Kinesiol. 2020, 53, 102438. [CrossRef] [PubMed]

46. Merletti, R.; Cerone, G.L. Tutorial. Surface EMG detection, conditioning and pre-processing: Best practices. J. Electromyogr. Kinesiol. 2020, 54, 102440. [CrossRef] [PubMed]

47. Merletti, R.; Muceli, S. Tutorial. Surface EMG detection in space and time: Best practices. J. Electromyogr. Kinesiol. 2019, 49, 102363. [CrossRef]

48. Vieira, T.M.; Botter, A. The Accurate Assessment of Muscle Excitation Requires the Detection of Multiple Surface Electromyograms. Exerc. Sport Sci. Rev. 2021, 49, 23-34. [CrossRef] [PubMed]

49. Del Vecchio, A.; Casolo, A.; Negro, F.; Scorcelletti, M.; Bazzucchi, I.; Enoka, R.; Felici, F.; Farina, D. The increase in muscle force after 4 weeks of strength training is mediated by adaptations in motor unit recruitment and rate coding. J. Physiol. 2019, 597, 1873-1887. [CrossRef] 
50. Trezise, J.; Blazevich, A.J. Anatomical and Neuromuscular Determinants of Strength Change in Previously Untrained Men Following Heavy Strength Training. Front. Physiol. 2019, 10, 1001. [CrossRef]

51. Cadore, E.L.; Gonzalez-Izal, M.; Grazioli, R.; Setuain, I.; Pinto, R.S.; Izquierdo, M. Effects of Concentric and Eccentric Strength Training on Fatigue Induced by Concentric and Eccentric Exercise. Int. J. Sports Physiol. Perform. 2019, 14, 91-98. [CrossRef]

52. Komi, P.V.; Buskirk, E.R. Effect of eccentric and concentric muscle conditioning on tension and electrical activity of human muscle. Ergonomics 1972, 15, 417-434. [CrossRef]

53. Purkayastha, S.; Cramer, J.T.; Trowbridge, C.A.; Fincher, A.L.; Marek, S.M. Surface electromyographic amplitude-to-work ratios during isokinetic and isotonic muscle actions. J. Athl. Train. 2006, 41, 314-320. [PubMed]

54. Rothstein, J.M.; Delitto, A.; Sinacore, D.R.; Rose, S.J. Electromyographic, peak torque, and power relationships during isokinetic movement. Phys. Ther. 1983, 63, 926-933. [CrossRef] [PubMed]

55. Bazzucchi, I.; Sbriccoli, P.; Marzattinocci, G.; Felici, F. Coactivation of the elbow antagonist muscles is not affected by the speed of movement in isokinetic exercise. Muscle Nerve 2006, 33, 191-199. [CrossRef] [PubMed]

56. Clancy, E.A.; Cairns, K.D.; Riley, P.O.; Meister, M.; Kerrigan, D.C. Effects of treadmill walking speed on lateral gastrocnemius muscle firing. Am. J. Phys. Med. Rehabil. 2004, 83, 507-514. [CrossRef] [PubMed]

57. Liu, M.Q.; Anderson, F.C.; Schwartz, M.H.; Delp, S.L. Muscle contributions to support and progression over a range of walking speeds. J. Biomech. 2008, 41, 3243-3252. [CrossRef] [PubMed] 